\title{
Acid-yield measurements of the gas-phase ozonolysis of ethene as a function of humidity using Chemical Ionisation Mass Spectrometry (CIMS)
}

\author{
K. E. Leather ${ }^{1}$, M. R. McGillen ${ }^{1, *}$, M. C. Cooke ${ }^{2}$, S. R. Utembe ${ }^{1,2}$, A. T. Archibald ${ }^{3}$, M. E. Jenkin ${ }^{2,4}$, R. G. Derwent ${ }^{5}$, \\ D. E. Shallcross ${ }^{2}$, and C. J. Percival ${ }^{1}$ \\ ${ }^{1}$ The Centre for Atmospheric Science, The School of Earth, Atmospheric and Environmental Science, The University of \\ Manchester, Simon Building, Brunswick Street, Manchester, M13 9PL, UK \\ ${ }^{2}$ Biogeochemistry Research Centre, School of Chemistry, The University of Bristol, Cantock's Close BS8 1TS, UK \\ ${ }^{3}$ Centre for Atmospheric Science, Department of Chemistry, University of Cambridge, Lensfield Road, Cambridge, \\ CB2 1EW, UK \\ ${ }^{4}$ Atmospheric Chemistry Services, Okehampton, Devon, EX20 1FB, UK \\ ${ }^{5}$ rdscientific, Newbury, Berkshire, UK \\ * current address: Chemical Sciences Division, Earth System Research Laboratory, National Oceanic and Atmospheric \\ Administration (NOAA), 325 Broadway, Boulder, CO 80305, USA
}

Correspondence to: C. J. Percival (c.percival@manchester.ac.uk)

Received: 19 July 2011 - Published in Atmos. Chem. Phys. Discuss.: 9 September 2011

Revised: 2 December 2011 - Accepted: 8 December 2011 - Published: 9 January 2012

\begin{abstract}
Gas-phase ethene ozonolysis experiments were conducted at room temperature to determine formic acid yields as a function of relative humidity (RH) using the integrated EXTreme RAnge chamber-Chemical Ionisation Mass Spectrometry technique, employing a $\mathrm{CH}_{3} \mathrm{I}$ ionisation scheme. RHs studied were $<1,11,21,27,30 \%$ and formic acid yields of $(0.07 \pm 0.01)$ and $(0.41 \pm 0.07)$ were determined at $<1 \% \mathrm{RH}$ and $30 \% \mathrm{RH}$ respectively, showing a strong water dependence. It has been possible to estimate the ratio of the rate coefficient for the reaction of the Criegee biradical, $\mathrm{CH}_{2} \mathrm{OO}$ with water compared with decomposition. This analysis suggests that the rate of reaction with water ranges between $1 \times 10^{-12}-1 \times 10^{-15} \mathrm{~cm}^{3}$ molecule ${ }^{-1} \mathrm{~s}^{-1}$ and will therefore dominate its loss with respect to bimolecular processes in the atmosphere. Global model integrations suggest that this reaction between $\mathrm{CH}_{2} \mathrm{OO}$ and water may dominate the production of $\mathrm{HC}(\mathrm{O}) \mathrm{OH}$ in the atmosphere.
\end{abstract}

\section{Introduction}

Organic acids are ubiquitous in the gas and aerosol phase, and are common constituents of global precipitation (Keene and Galloway, 1983). Organic acids have been measured in urban, rural, marine and remote areas (Talbot et al., 1988; Chebbi and Carlier, 1996; Kawamura et al., 2001). The contribution of organic acids to the acidity of precipitation and subsequent effects on aquatic and terrestrial ecosystems has been documented by Keene and Galloway (1986). Formic and acetic acid can dominate free acidity of precipitation thereby having an influence on $\mathrm{pH}$-dependent chemical reactions and even OH cloud chemistry (Jacob et al., 1986). Low molecular weight organic salts - presumably the product of organic acid dissolution - are present in the fine fraction of aerosols, whose physical properties, namely hygroscopicity, possess relatively low critical supersaturations, allowing the activation of cloud droplets and subsequently affecting total indirect radiative forcing (Yu, 2000).

Sources of carboxylic acids include biogenic and anthropogenic primary emissions, biomass burning and 
hydrocarbon oxidation, though their relative fluxes are poorly constrained (Chebbi and Carlier, 1996; Paulot et al., 2011). The major sinks of carboxylic acids are dry and wet deposition as a result of their low reactivity towards $\mathrm{OH}$ and $\mathrm{NO}_{3}$. However, the chemical loss via reaction with $\mathrm{OH}$ is poorly constrained resulting from the uncertainty in the reported rate coefficient (Atkinson et al., 2006). The modelled atmospheric lifetime of formic acid has been calculated to be 3.2 days (Paulot et al., 2011).

Global models under predict formic acid concentrations (von Kuhlmann et al., 2003; Rinsland et al., 2004; Paulot et al., 2011) especially in the marine boundary layer where $[\mathrm{HC}(\mathrm{O}) \mathrm{OH}]$ can be underestimated by a factor of $10-50$, this discrepancy has been attributed to missing sources such as higher biogenic emissions during the growing season (Rinsland et al., 2004) and ageing of organic aerosols (Paulot et al., 2011). Also, the oxidation of VOC precursors leading to the production of formic acid has been suggested to be a significant source (Arlander et al., 1990), for instance the ozonolysis of ethene. Ethene emissions have been estimated to be about $15 \mathrm{Tg} \mathrm{yr}^{-1}$ (EDGAR, 1996) with about $162 \mathrm{Gmol} \mathrm{yr}^{-1}$ from the oceans (Paulot et al., 2011), and the presence of a major formic acid-producing reaction channel would therefore be of major importance to atmospheric chemical modelling.

This study focuses on the production of formic acid from ethene ozonolysis. Intuitively, monitoring the products of this reaction ought to be easier than many ozonolysis reactions since the first-generation products possess a carbon number of one and are likely to be of maximum volatility. However, there still remain considerable inconsistencies in formic acid yields reported in the literature (Neeb et al., 1997; Wolff et al., 1997; Orzechowska and Paulson, 2005). Ozonolysis proceeds via a 1,3-cycloaddition across the olefinic bond to produce a primary ozonide, the decomposition of which forms a carbonyl moiety and a Criegee biradical each with unit yield (Scheme 1).

It is the fate of the Criegee biradical that determines the end product yield and this has provoked much attention in the atmospheric chemistry community (Johnson and Marston, 2008 and references therein). Here the mechanisms highlighted shall focus on acid production pathways. It was first suggested by O'Neal and Blumstein (1973) that the Criegee biradical may isomerise to form a dioxirane intermediate, leading to the formation of carboxylic acids, as detailed by Orzechowska and Paulson (2005), this hypothesis is supported by the theoretical calculations of Cremer et al. (1998) (Scheme 2).

Formic acid may also be produced from bimolecular reactions. Calvert et al. (1978) suggested that in the presence of water, acid production can be significantly enhanced via reaction of the stabilised Criegee radical with water (Scheme 3). The formation of $\mathrm{HC}(\mathrm{O}) \mathrm{OH}$ via Scheme 3 has been further supported by the theoretical results of Hatakeyama et al. (1981), Crehuet et al. (2001) and Anglada

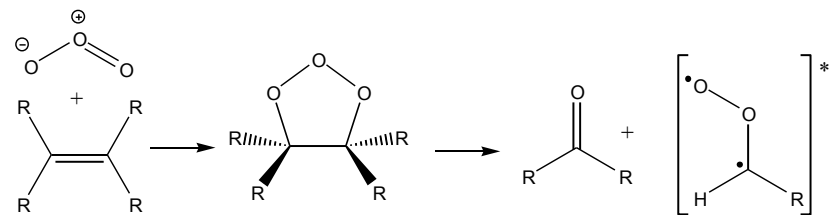

Scheme 1. A schematic diagram of the reaction mechanism of ozonolysis of alkenes.

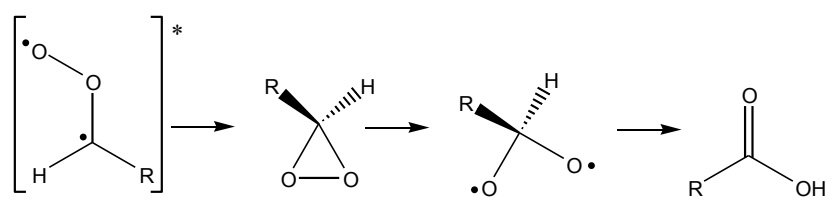

Scheme 2. A schematic diagram of the formation of $\mathrm{HC}(\mathrm{O}) \mathrm{OH}$ under dry conditions.

et al. (2002). Minor pathways such as cross reactions of reactive intermediates can form secondary ozonides, for instance reaction between Criegee biradicals and carbonyls, which have been suggested to lead to the formation of acids (Neeb et al., 1996).

Despite the importance of these formic acid-producing channels, there have been relatively few experimental determinations of $\mathrm{HC}(\mathrm{O}) \mathrm{OH}$ yields from the ozonolysis of ethene. Wolff et al. (1997) and Orzechowska and Paulson (2005) report high formic acid yields (0.36) for ethene ozonolysis conducted in dry conditions compared with that of Neeb et al. (1997) (0.01) (see Table 1). Discrepancies in yields reported under humid conditions also exist as Neeb and coworkers obtain 0.42 at $65 \%$ RH yet Orzechowska and Paulson report 0.33 at $65 \%$ RH. Wolff et al. (1997) and Orzechowska and Paulson (2005) both use indirect analytical techniques to quantify acid yields, whereas Neeb et al. (1997) use FTIR. All the techniques have the potential for significant errors as a result of sampling efficiency, spectral overlap and low sensitivity. This study aims to resolve the discrepancy by quantifying acid yields using the highly selective and sensitive technique, Chemical Ionisation Mass Spectrometry (CIMS).

\section{Experimental}

Experiments were conducted in the dark in the $123 \mathrm{~L}$ Teflon ${ }^{\circledR}$-coated EXTRA chamber, described in detail elsewhere (Leather et al., 2010, 2011 and McGillen et al., 2011), and shown in Fig. 1. FVMQ o-ring seals within the end flanges ensured that the chamber was leak tight, whilst reinforcement ribs afford maximum pressures of 3750 Torr. Seven sample ports are incorporated into the end flanges, to enable simultaneous sampling by a range of analytical techniques. The EXTRA chamber can be operated over 


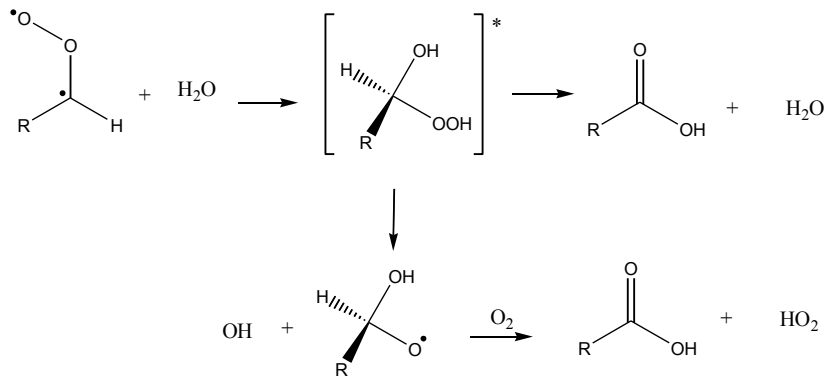

Scheme 3. A schematic diagram of the formation of $\mathrm{HC}(\mathrm{O}) \mathrm{OH}$ under wet conditions.

Table 1. Formic acid yields previously reported, to the best of our knowledge.

\begin{tabular}{lll}
\hline RH \% & HC(O)OH yield & \\
\hline 0 & $0.36 \pm 0.05$ & Wolff et al. (1997) \\
& $0.36 \pm 0.07$ & Orzechowska and Paulson (2005) \\
& 0.01 & Neeb et al. (1997) \\
20 & $0.4 \pm 0.13$ & Wolff et al. (1997) \\
65 & 0.42 & Neeb et al. (1997) \\
65 & $0.33 \pm 0.06$ & Orzechowska and Paulson (2005) \\
\hline
\end{tabular}

the temperature range $193-473 \mathrm{~K}$ and pressure range $1-$ 3750 Torr. Temperature control also allowed two day bake out cleaning procedures to be performed between experiments. Despite the volume of EXTRA being modest (surface: volume $=0.12)$ a combination of $100 \%$ Teflon ${ }^{\circledR}$ surfaces, and temperature and pressure control results in a system of minimal wall losses with respect to oxidants and condensable hydrocarbons.

Quantitative ozone decay measurements were taken at $10 \mathrm{~s}$ time intervals, after allowing 5 min mixing time. Absolute ozone concentrations were measured using a Monitor Labs Inc. Ozone Analyzer (model 8810) through UV absorption at $254 \mathrm{~nm}$ (supplied from a mercury discharge lamp). Ozone was produced by flowing purified compressed air or oxygen (BOC, zero grade) through a UVP ozone generator (97-0067-02) into the chamber containing an atmosphere of nitrogen (BOC, oxygen free). The first-order decay rate of ozone with respect to walls and thermal decomposition using this continuous sampling configuration was found to be $6.94 \times 10^{-6} \mathrm{~s}^{-1}$ and thus were considered negligible with respect to the timescale of the experiments.

Quantitative concentration-time profiles of $\mathrm{HC}(\mathrm{O}) \mathrm{OH}$ were determined using CIMS. The CIMS was coupled to the EXTRA chamber through a sample port via $70 \mathrm{~cm}$ of $1 / 8^{\prime \prime}$ o.d. PFA tubing. CIMS sampled through a critical orifice at a flow rate of 0.8 SLM at 760 Torr and $\sim 296 \mathrm{~K}$ with a residence time of $0.1 \mathrm{~s}$ in the sample line preceding the ion molecule region.
$\mathrm{HC}(\mathrm{O}) \mathrm{OH}$ was detected using $\mathrm{I}^{-}$as the reagent ion. $\mathrm{I}^{-}$ was generated by combining a $1.5 \mathrm{STP} 1 \mathrm{~min}^{-1}$ flow of $\mathrm{N}_{2}$ and a $1 \mathrm{sccm}$ flow of $0.5 \% \mathrm{CH}_{3} \mathrm{I} / \mathrm{H}_{2} \mathrm{O} / \mathrm{N}_{2}$ gas mixture and passing it through a Po(210) Nuclecel ionizer (NRD Inc.). $\mathrm{HC}(\mathrm{O}) \mathrm{OH}$ was ionised by $\mathrm{I}^{-}$via an adduct reaction,

$\mathrm{I}^{-} \cdot \mathrm{H}_{2} \mathrm{O}_{n}+\mathrm{HC}(\mathrm{O}) \mathrm{OH} \rightarrow \mathrm{HC}(\mathrm{O}) \mathrm{OH} \cdot \mathrm{I}^{-} \cdot \mathrm{H}_{2} \mathrm{O}_{n}$

which enabled formic acid to be detected selectively at $m / z=171.65$ (Slusher et al., 2004).

Ions were detected with a quadrupole mass spectrometer in a three-stage differentially pumped vacuum chamber, as shown in Fig. 2. A sample of the ion molecule gas flow containing reactant ions is drawn into the collision dissociation chamber through a $0.38 \mathrm{~mm}$ aperture which was held at a potential of $-0.17 \mathrm{~V}$ to focus charged reactant molecules. The collision dissociation chamber was pumped by a molecular drag pump (Alcatel MDP-5011) backed by a scroll pump (ULVAC DISL-100) and held at approximately 20 Torr. The ions were further focused by an octopole ion guide, stainless steel with a $1.00 \mathrm{~mm}$ aperture held at $-0.36 \mathrm{~V}$ and passed into a second chamber containing the further octopole ion guide and passed into the rear chamber via a stainless steel plate with a $1.00 \mathrm{~mm}$ aperture held at $-0.48 \mathrm{~V}$ which contained the quadrupole mass filter (ABB Extrel, Merlin). This second and rear chamber were each pumped by a turbomolecular pump (Varian 81-M) backed by the molecular drag pump (Alcatel MDP-5011). Under typical operating conditions the rear chamber was held at a pressure of approximately $9 \times 10^{-6}$ Torr. Ions were detected using a channeltron (Dtech 402A-H) via negative ion counting.

Gaseous reagents were added to the chamber at a known flow rate and duration using calibrated 1179 MKS mass flow controllers. The chamber contained an atmosphere of nitrogen preceding the addition of reagent gases. Ethene was introduced from a dilute ethene/nitrogen gas mixture. Ozone was produced by flowing oxygen through a UVP ozone generator (97-0067-02).

For the addition of water or formic acid, known volumes were injected into a Pyrex impinger, becoming volatilised by exposure to the evacuated chamber, assisted by an additional nitrogen carrier gas purge. The initial reactant concentrations were varied as follows; $\left[\mathrm{O}_{3}\right]$ $=2.46 \times 10^{12}-9.84 \times 10^{13}$ molecule $\mathrm{cm}^{-3}, \mathrm{H}_{2} \mathrm{O} \leq 1-30 \% \mathrm{RH}$ and $\mathrm{C}_{2} \mathrm{H}_{4}=4.92 \times 10^{13}-2.23 \times 10^{15}$ molecule $\mathrm{cm}^{-3}$.

\section{Materials}

Ethene (Sigma Aldrich, 99.54\%) was purified by repeated freezepumpthaw cycles. $\mathrm{N}_{2}, \mathrm{O}_{2}(99.6 \%)$ were used as supplied. Formic acid (Fisher Scientific UK, 98/100\%) was used without further purification. Purified water $(\geq 15.0 \mathrm{M} \Omega$ $\mathrm{cm}$ ) was obtained from a PURELAB Option-S 7/15 (ELGA). 


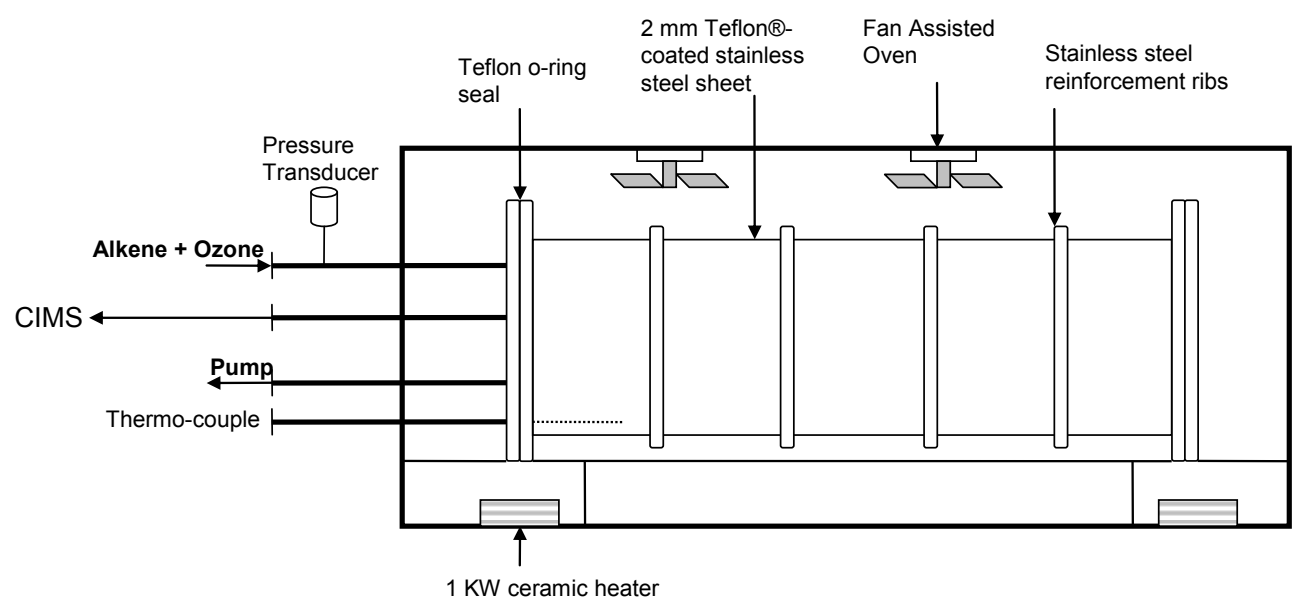

Fig. 1. A schematic diagram of the EXTRA chamber.

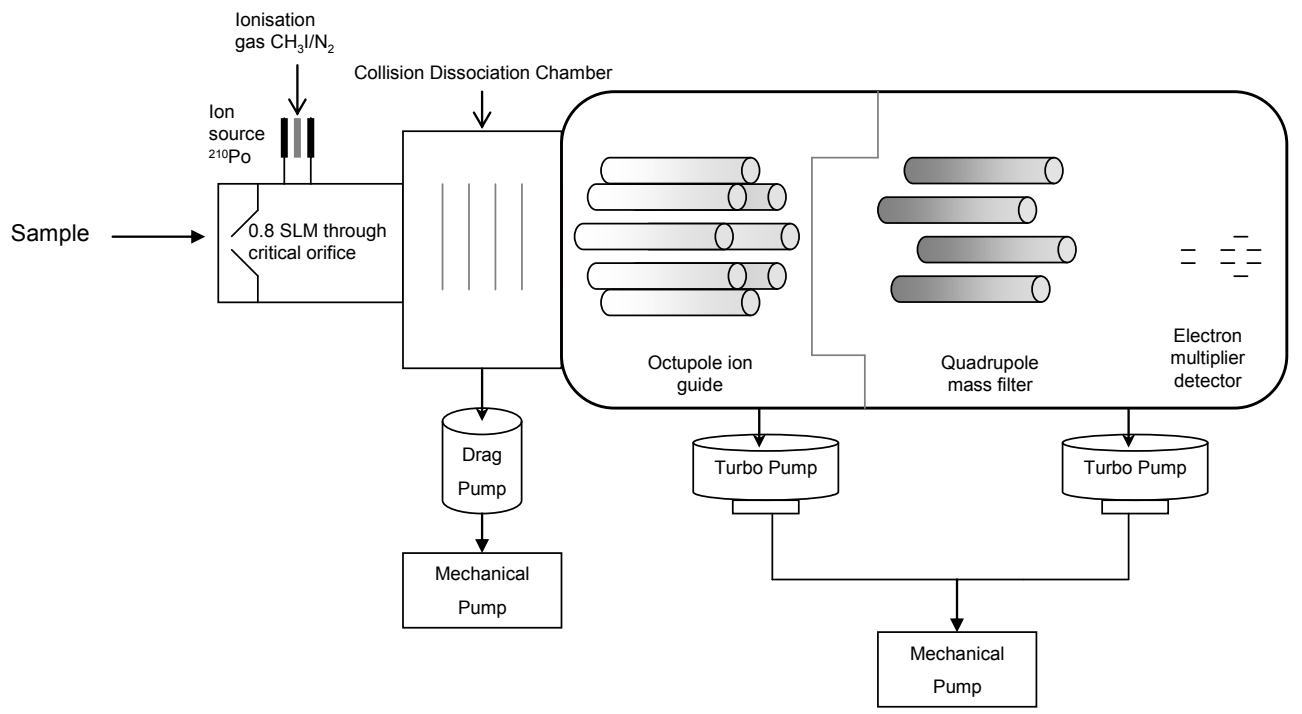

Fig. 2. A schematic diagram of the CIMS system.

\subsection{Global model description}

The Global Chemistry Transport model CRI-STOCHEM has been used to assess the mass of products formed in the atmosphere using data from this study. CRI-STOCHEM is described in detail in (Utembe et al., 2010 and Archibald et al., 2010). The model used is an updated version of the UK Meteorological Office tropospheric chemistry transport model (STOCHEM) described by Collins et al. (1997), with updates reported in detail in the recent paper of Utembe et al. (2010). STOCHEM is a global 3-dimensional CTM which uses a Lagrangian approach to advect 50000 air parcels using a 4th-order Runge-Kutta scheme with advection time steps of 3 hours. The transport and radiation models are driven by archived meteorological data, generated by the Met office numerical weather prediction models as analysis fields with a resolution of $1.25^{\circ}$ longitude and $0.83^{\circ}$ latitude and on 12 vertical levels extending to $100 \mathrm{hPa}$. Full details of the model version employed are given in Derwent et al. (2008).

The common representative intermediates mechanism (CRIv2-R5) (Jenkin et al., 2008; Watson et al., 2008; Utembe et al., 2009), which represents the chemistry of methane and 22 emitted non-methane hydrocarbons was employed in the model. Each parcel contains the concentrations of 219 species involved in 618 photolytic, gas-phase and heterogeneous chemical reactions, with a $5 \mathrm{~min}$ time step. The formation of secondary organic aerosol (SOA) is represented using 14 species, which are derived from the oxidation of aromatic hydrocarbons, monoterpenes, and isoprene (see Utembe et al., 2011).

The surface emissions (man-made, biomass burning, vegetation, oceans, soil and "other" surface emissions) are 
distributed using two-dimensional source maps. Emissions totals for the base case run for $\mathrm{CO}, \mathrm{NO}_{\mathrm{x}}$ and non-methane hydrocarbons are taken from the Precursor of Ozone and their Effects in the Troposphere (POET) inventory (Granier, et al., 2005) for the year 1998. The emission of aromatic species ortho-xylene, benzene and toluene were taken from Henze et al. (2008). Biomass burning emission of ethyne, formaldehyde and acetic acid are produced using scaling factors from Andreae and Merlet (2001) per mole of CO emitted. NASA inventories are used for aircraft $\mathrm{NO}_{\mathrm{x}}$ emissions for 1992 taken from Penner et al. (1999). The lightning and aircraft $\mathrm{NO}_{\mathrm{x}}$ emissions are monthly averages and are 3-dimensional in distribution.

\section{Results and discussion}

\subsection{Assessment of instrument sensitivity.}

Dilute mixtures of $\mathrm{HC}(\mathrm{O}) \mathrm{OH}$ in deionized water were injected into the Chamber with no other gases present and the $\mathrm{HC}(\mathrm{O}) \mathrm{OH} . \mathrm{I}^{-}$signal was monitored. From a linear plot of $[\mathrm{HC}(\mathrm{O}) \mathrm{OH}]$ vs. $\mathrm{HC}(\mathrm{O}) \mathrm{OH} \cdot \mathrm{I}^{-}$signal it is estimated that the sensitivity for $\mathrm{HC}(\mathrm{O}) \mathrm{OH}$ was $2.39 \times 10^{7}$ molecule $\mathrm{cm}^{-3}$ for a signal to noise ratio of one and a time constant of $1 \mathrm{~s}$.

\subsection{Rate coefficient determination}

The gas-phase rate coefficient of the reaction of ethene with ozone was determined using the absolute method. The rate equation is shown in Eq. (2);

$-d \ln \left[\mathrm{O}_{3}\right] / d t=k /[$ ethene $]$

where $k^{\prime}$ is the pseudo-first order rate coefficient given by $k^{\prime}=k\left[\mathrm{O}_{3}\right]$. For each experiment, the slope $k^{\prime}$ was obtained using the linear regression of $\ln \left[\mathrm{O}_{3}\right]$ vs. time for a broad range of alkene concentrations. First-order plots exhibited linear decays, (Fig. 3) having typical $R^{2}$ of 0.99 , indicating first-order kinetic behaviour. The plot of $k^{\prime}$ vs. initial [ethene] also exhibited a strong linear relationship, from which the gradient $k$, the bimolecular rate coefficient for the reaction was determined (Fig. 4). The rate was found to be $(1.62 \pm 0.14) \times 10^{-18} \mathrm{~cm}^{3}$ molecule ${ }^{-1} \mathrm{~s}^{-1}$, in excellent agreement with the literature recommendation (Atkinson et al., 2000).

\subsection{Product yields}

Product yields were determined in excess ethene conditions, in excess typically by a factor of 300-400. Initial comparison of $\mathrm{HC}(\mathrm{O}) \mathrm{OH}$ signal shows that $[\mathrm{HC}(\mathrm{O}) \mathrm{OH}]$ at $\mathrm{RH} 30 \%$ exceeds that of $\mathrm{RH}<1 \%$ by more than a factor of 7 , in the initial stages during ethene ozonolysis, which suggests that reaction Scheme 3 dominates in the presence of water. Figure 5 shows two temporal profiles of the formic acid produced. The curve passing through the $[\mathrm{HC}(\mathrm{O}) \mathrm{OH}]$ exper-

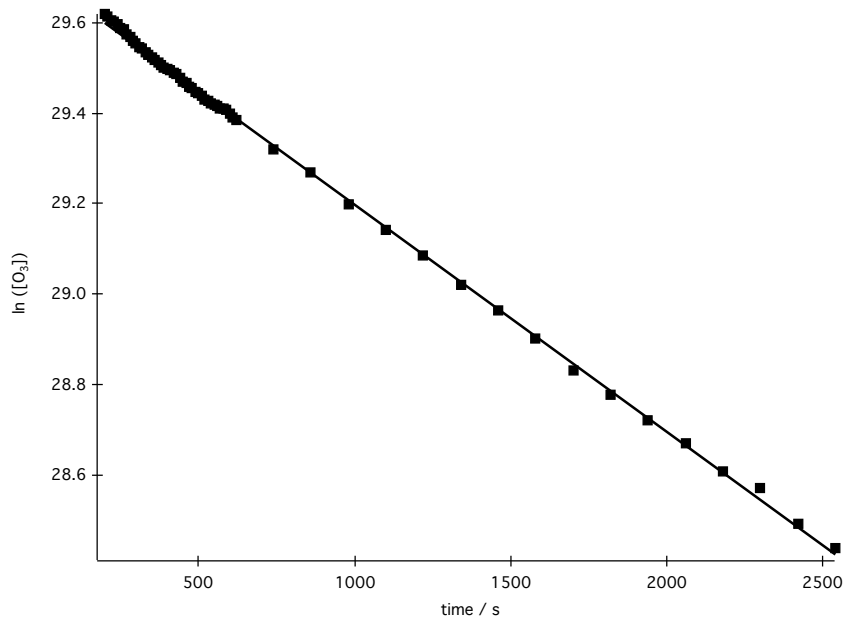

Fig. 3. Temporal plot of ozone decay to yield $k^{\prime}$, with an initial [ethene] of $10.5 \mathrm{ppm}$.

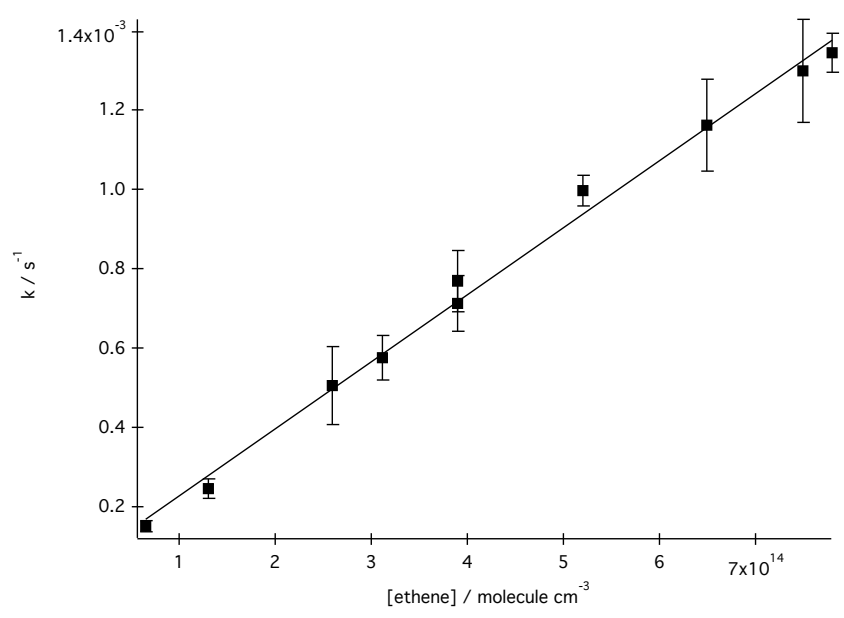

Fig. 4. Second-order plot of $k^{\prime}$ vs. [ethene].

imentally determined values utilises the literature retrieved rate coefficient of $1.58 \times 10^{-18} \mathrm{~cm}^{3}$ molecule ${ }^{-1} \mathrm{~s}^{-1}$ (Atkinson et al., 2000) and the line of best fit is obtained by varying the branching ratio to $\mathrm{HC}(\mathrm{O}) \mathrm{OH}$ formation. [ $\mathrm{HC}(\mathrm{O}) \mathrm{OH}]$ yields were quantified as a function of relative humdity $(\mathrm{RH})$, as summarised in Table 2.

In Fig. 6 it is clear to see that the formic acid yield increases from $\mathrm{RH}<1-30 \%$, in keeping with the work of Neeb et al. (1997) but in disagreement with the work of Orzechowska and Paulson (2005). Between 20-30\% RH the increase is less pronounced but still apparent. There are several possible explanations for the observed behaviour and each will be discussed in the next section. Previous studies of the ozonolysis of alkenes have chosen to refer to Criegee biradicals formed during ozonolysis as either stabilised or unstabilised (e.g. Kroll et al., 2001a, b; Johnson and Marston, 2008). In the ozonolysis reaction, ozone reacts with the 


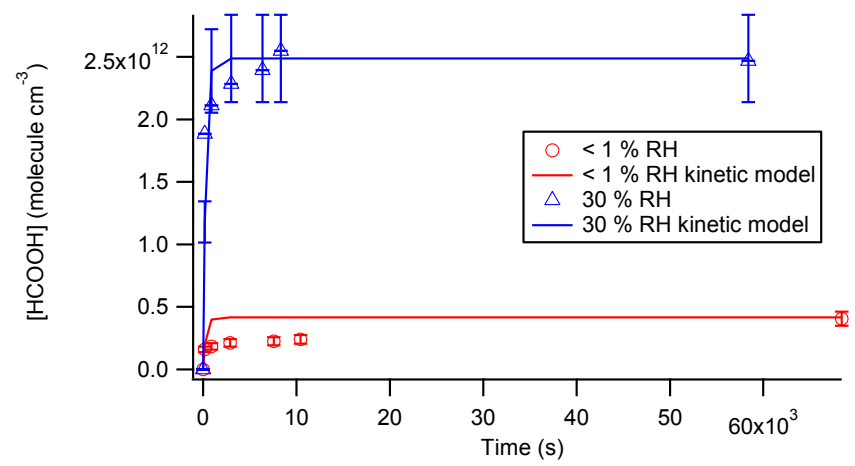

Fig. 5. Retrieved experimental values of $[\mathrm{HC}(\mathrm{O}) \mathrm{OH}]$ and kinetically derived modelled trend line for ethene ozonolysis under RH $<1 \%$ and $30 \%$ conditions.

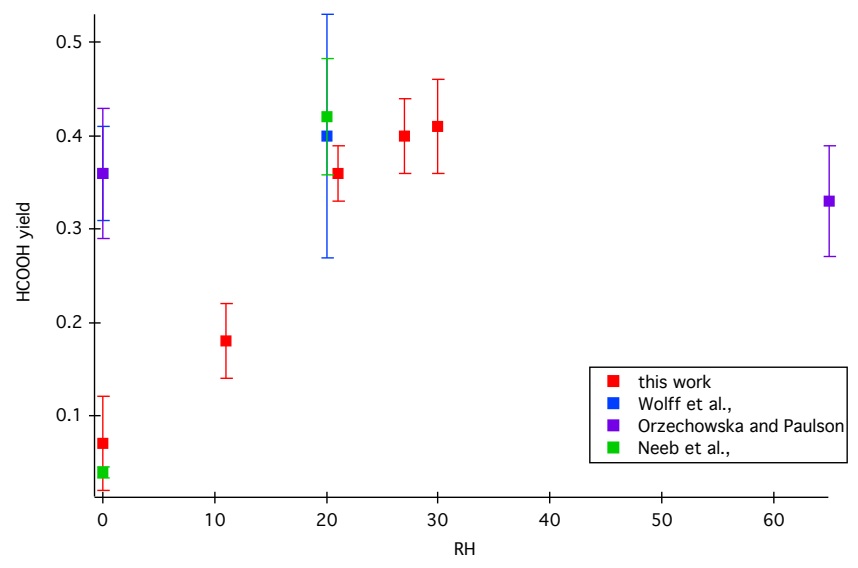

Fig. 6. A comparison of the experimentally determined $\mathrm{HC}(\mathrm{O}) \mathrm{OH}$ yields as a function of $\mathrm{RH}$.

olefinic bond of an alkene through a 1,3-cycloaddition forming a primary ozonide, which decomposes to form a Criegee biradical and a carbonyl coproduct. This nascent Criegee biradical may possess a range of (vibrational) energies and depending on energy barriers, a certain fraction will be able to isomerise or decompose (unstabilised), with the remainder being below these energy barriers (stabilised), affording a long enough lifetime to be able to undergo bimolecular reactions. As pressure is increased more Criegee biradicals will be "stabilised' as a result of collisional quenching. The results of the $\mathrm{HC}(\mathrm{O}) \mathrm{OH}$ yield as a function of $\mathrm{RH}$ can be analysed using two possible scenarios:

\subsection{Scenario 1}

In a scenario where all Criegee biradicals are in a stabilised form in this system then it is possible to model the $\mathrm{HC}(\mathrm{O}) \mathrm{OH}$ yield as a function of RH. It is assumed that the Criegee radical has one of two fates, reaction with $\mathrm{H}_{2} \mathrm{O}$ to form $\mathrm{HC}(\mathrm{O}) \mathrm{OH}$ (Reaction R3) or decomposition (possibly wall
Table 2. A summary of the experimentally determined $\mathrm{HC}(\mathrm{O}) \mathrm{OH}$ yield obtained in this study, errors quoted are at the $1 \sigma$ level of sensitivity calibrations.

\begin{tabular}{ll}
\hline RH $\%$ & HC(O)OH Yield \\
\hline$<1$ & $0.07 \pm 0.01$ \\
11 & $0.18 \pm 0.03$ \\
21 & $0.36 \pm 0.05$ \\
27 & $0.40 \pm 0.06$ \\
30 & $0.41 \pm 0.06$ \\
\hline
\end{tabular}

loss) independent of $\mathrm{H}_{2} \mathrm{O}$. This model can be summarised by the two reactions

$$
\begin{aligned}
& \mathrm{CH}_{2} \mathrm{OO}+\mathrm{H}_{2} \mathrm{O} \rightarrow \mathrm{HC}(\mathrm{O}) \mathrm{OH}+\mathrm{H}_{2} \mathrm{O} \\
& \mathrm{CH}_{2} \mathrm{OO} \rightarrow \text { products }
\end{aligned}
$$

A simple model encapsulating these two Reactions (R3) and (R4) is compared with measurement data in Fig. 7. Here, the yield of $\mathrm{HC}(\mathrm{O}) \mathrm{OH}$ is defined as

$$
\mathrm{HCOOH}_{\text {yield }}=\frac{k_{3}\left[\mathrm{H}_{2} \mathrm{O}\right]}{k_{3}\left[\mathrm{H}_{2} \mathrm{O}\right]+k_{4}}
$$

Clearly it is not possible to obtain a unique fit to the experimental data as there are no direct measurements of the rate of reaction of the Criegee radical with water $\left(k_{3}\right)$. Indeed, estimates for the reaction rate of the Criegee radical with water range over three orders of magnitude (Calvert et al., 2000). However, a ratio between $k_{3}$ and $k_{4}$ emerges, where $k_{4} / k_{3}$ is $3.3 \times 10^{17}$ molecule $\mathrm{cm}^{-3}$ to obtain an excellent fit to the measurement data. Assuming that $k_{3}$ has a maximum value of around $1.5 \times 10^{-10} \mathrm{~cm}^{3}$ molecule ${ }^{-1} \mathrm{~s}^{-1}$ (gas kinetic limit) this puts an upper limit on the decomposition rate of the stabilised Criegee biradical of $5 \times 10^{7} \mathrm{~s}^{-1}$, similarly, if $k_{3}$ is around $1.5 \times 10^{-17} \mathrm{~cm}^{3}$ molecule ${ }^{-1} \mathrm{~s}^{-1}$ as suggested by indirect measurements then $k_{4}$ is only $5 \mathrm{~s}^{-1}$, much lower than theoretical (e.g. Ryzhkov and Ariya, 2004) estimates. Indeed, the work of Ryzhkov and Ariya (2004) suggest a value of $k_{4}$ between $5 \times 10^{5} \mathrm{~s}^{-1}$ and $5 \times 10^{2} \mathrm{~s}^{-1}$, which provides a range for $k_{3}$ of $1.5 \times 10^{-12} \mathrm{~cm}^{3}$ molecule $^{-1} \mathrm{~s}^{-1}$ $1.5 \times 10^{-15} \mathrm{~cm}^{3}$ molecule ${ }^{-1} \mathrm{~s}^{-1}$.

\subsection{Scenario 2}

Alternatively, in a scenario where all Criegee biradicals are in an unstabilised form in this system then it is also possible to model the $\mathrm{HC}(\mathrm{O}) \mathrm{OH}$ yield as a function of $\mathrm{RH}$. Following the work of Kroll et al. (2001a, b), we note that for unstabilised $\mathrm{CH}_{2} \mathrm{OO}$ biradicals, the dominant fate is to isomerise to dioxirane which can then rearrange to form $\mathrm{HC}(\mathrm{O}) \mathrm{OH}$ in a vibrationally excited state, the so called "hot acid" channel. This hot acid can either be stabilised (here by water as well as the bath gas) or decompose to form $\mathrm{OH}$. A similar model 


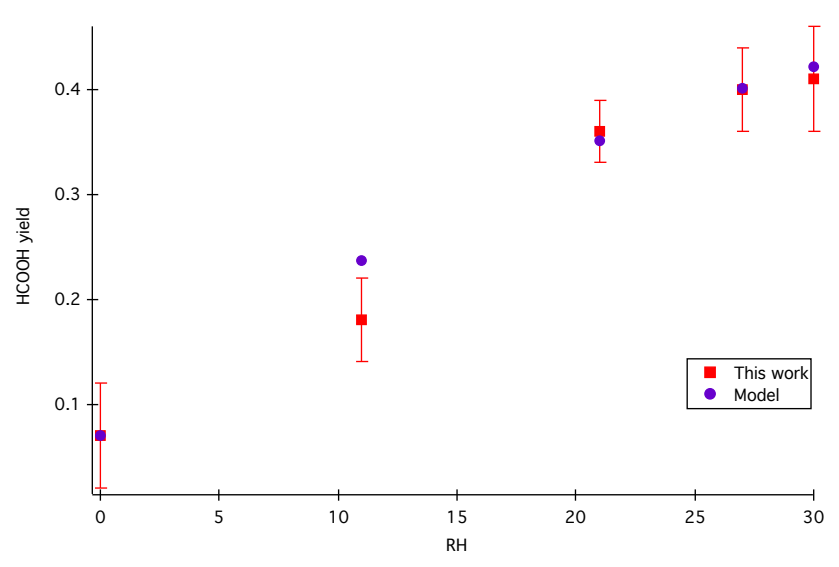

Fig. 7. Modelled $\mathrm{HC}(\mathrm{O}) \mathrm{OH}$ yields as a function of $\mathrm{RH} \%$.

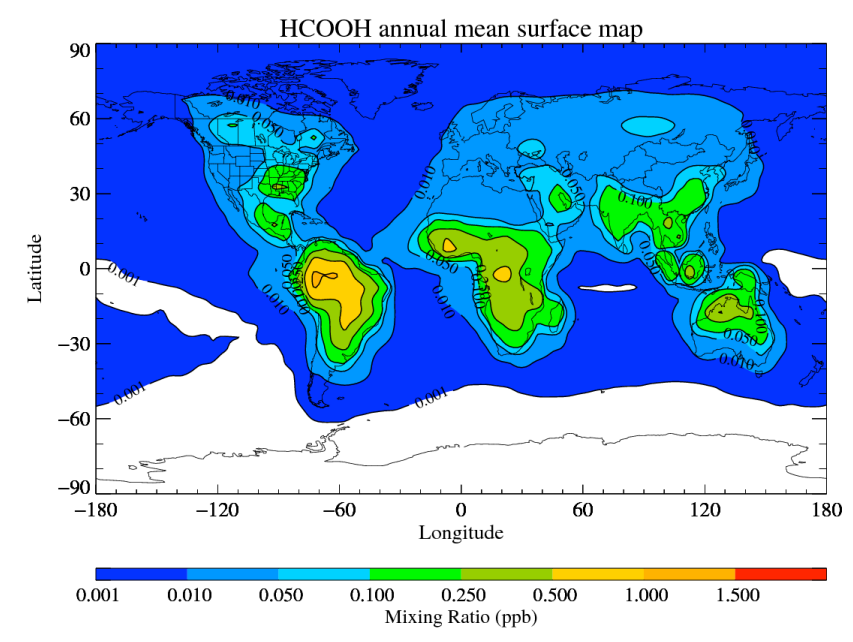

Fig. 8. The annual mean surface formic acid derived from the base case model run.

analysis can be proposed where Reaction (R3) involves stabilisation of the hot acid and Reaction (R4) its decomposition

$\mathrm{HC}(\mathrm{O}) \mathrm{OH}^{*}+\mathrm{H}_{2} \mathrm{O} \rightarrow \mathrm{HC}(\mathrm{O}) \mathrm{OH}+\mathrm{H}_{2} \mathrm{O}$

$\mathrm{HC}(\mathrm{O}) \mathrm{OH}^{*} \rightarrow$ products

Which results in a similar expression for the yield of $\mathrm{HC}(\mathrm{O}) \mathrm{OH}$

$\mathrm{HCOOH}_{\text {yield }}=\frac{k_{6}\left[\mathrm{H}_{2} \mathrm{O}\right]}{k_{6}\left[\mathrm{H}_{2} \mathrm{O}\right]+k_{7}}$

Once again it is not possible to obtain a unique fit to the experimental data as there are no direct measurements of either $k_{6}$ or $k_{7}$. However, a ratio between $k_{6}$ and $k_{7}$ as in scenario 1 means that $k_{7} / k_{6}$ is $3.3 \times 10^{17}$ molecule $\mathrm{cm}^{-3}$ to obtain an excellent fit to the measurement data. Since $k_{6}$ represents a collision rate it is reasonable to estimate it to be around $1.5 \times 10^{-10} \mathrm{~cm}^{3}$ molecule ${ }^{-1} \mathrm{~s}^{-1}$ (gas kinetic limit) which provides a value for the decomposition rate of the unstabilised Criegee bi-radical of approximately $5 \times 10^{7} \mathrm{~s}^{-1}$.

A variety of experiments and theoretical investigations suggest that between $35 \%-54 \%$ (Alam et al., 2011) of the $\mathrm{CH}_{2} \mathrm{OO}$ formed are stabilised and it is assumed that the rest must be unstabilised. The production of $\mathrm{OH}$, believed to arise predominantly (exclusively) from unstabilised $\mathrm{CH}_{2} \mathrm{OO}$ is reported to be between $0-22 \%$ of all Criegee biradicals formed (Alam et al., 2011). Data from this work suggests that the yield of $\mathrm{HC}(\mathrm{O}) \mathrm{OH}$ is at least $40 \%$ and indeed is still increasing at the highest water vapour investigated. Hence, if the lower estimates for the fraction of stabilised $\mathrm{CH}_{2} \mathrm{OO}$ are correct ( $\sim 35-40 \%)$, then $\mathrm{HC}(\mathrm{O}) \mathrm{OH}$ must also be formed from unstabilised $\mathrm{CH}_{2} \mathrm{OO}$, presumably via quenching of the "hot acid".

Hence, current research suggests that scenario 1 could represent up to about $54 \%$ of $\mathrm{CH}_{2} \mathrm{OO}$ formed. If it is assumed that all the observed $\mathrm{HC}(\mathrm{O}) \mathrm{OH}$ is from this channel only and that the maximum yield is 0.54 , then $k_{4} / k_{3}$ is $\sim 1 \times 10^{17}$ molecule $\mathrm{cm}^{-3}$ and the value for $k_{3}$ is larger still than estimated in scenario 1, although this study cannot provide a unique value. Can scenario 2 exist? If the lowest evaluations of the amount of stabilised $\mathrm{CH}_{2} \mathrm{OO}$ are correct, then it would appear that stabilisation is occurring at atmospheric pressure with the increasing relative humidity. Indeed, at high pressures stabilisation must occur, although there is considerable debate as to the value required to approach this high pressure limit. This is further supported by the results of Alam et al. (2011) who report a decrease in radical yield with increased RH, i.e. the stabilised Criegee radical is being removed via reaction with water. In an analogous system, the ozonolysis of alpha pinene, Tillmann et al. (2010) report an increase in the yield of pinonaldhyde with $\mathrm{RH}$ as a result of the increased titration of the SCI with water. The result of Tillmann et al. (2010) would suggest the reaction of SCI with water is a ubiquitous phenomenon with far reaching implications for tropospheric chemistry.

In order to further investigate this system and obtain experimental evidence to validate the production of hydroxymethylhydroperoxide (HMHP) during ethene ozonolysis, HMHP was synthesized according to accepted synthesis described by Marklund et al. (1971) and Neeb et al. (1997). The existence of HMHP was confirmed by the appearance of an absorption band at $950-1075 \mathrm{~cm}^{-1}$ (Bauerle, 1999; Minkoff, 1954). However, using $\mathrm{I}^{-}$chemistry, the CIMS instrument was not sensitive to the detection of HMHP, though this does not rule out HMHP production and the detection of HMHP could be achieved using an alternative ionisation scheme or an additional analytical technique. Wolff et al. (1997) did not observe enhancement of HMHP in humid conditions and so do not accept scheme 3 to be responsible for acid production as a result of alkene ozonolysis. However, Neeb et al. (1997) detect high HMHP yields during ethene ozonolysis though they suggest that secondary chemistry through heterogeneous processes led to acid formation. 
Recent theoretical work (Anglada et al., 2002) suggests that $\mathrm{HC}(\mathrm{O}) \mathrm{OH}$ is produced via the formation of HMHP through a Criegee intermediate water complex, and $\mathrm{HC}(\mathrm{O}) \mathrm{OH}$ yields increase as a result of increasing relative humidity, which supports the observation of this study.

The formic acid product yields obtained in this study are in good agreement with Neeb et al. (1997) across the range of RH studied. However, this work disagrees with dry yields reported by Wolff et al. (1997) and by Orzechowska and Paulson (2005). Both studies utilise an indirect method of detection of $\mathrm{HC}(\mathrm{O}) \mathrm{OH}$, which involves a sampling step. Orzechowska and Paulson suggest that formic acid is not a major product of ethene ozonolysis and attribute acid production to the decomposition of HMHP on the solid-phase microextraction (SPME) fibre sampling system. This explanation is somewhat paradoxical, since if HMHP decomposition caused spuriously high acid yields in dry conditions, it is uncertain why HMHP was present in the system in the first place given that its formation is dependent on the presence of water (see Scheme 3). Wolff et al. (1997) also observe large formic acid yields at low RH. However, the formic acid yield that they observe is the sum of primary formic, formic anhydride and HPMF, which could explain the discrepancy under dry conditions.

CIMS is the most sensitive technique to date used to probe the production of $\mathrm{HC}(\mathrm{O}) \mathrm{OH}$ in the ethene $+\mathrm{O}_{3}$ system. Whilst CIMS is selective to $\mathrm{HC}(\mathrm{O}) \mathrm{OH}$ there still remains the possibility that formic acid production is enhanced by heterogeneous processes during ethene ozonolysis. Temperature and pressure control allow this system to be baked out during cleanout procedures, producing a small measured $k_{w}$ (wall loss rate coefficient) with respect to ozone and $\mathrm{HC}(\mathrm{O}) \mathrm{OH}$ and so one can expect little impact on $\mathrm{HC}(\mathrm{O}) \mathrm{OH}$ yields from heterogeneous losses. The first-order decay rate of ozone and $\mathrm{HC}(\mathrm{O}) \mathrm{OH}$ with respect to walls were determined to be $6.94 \times 10^{-6} \mathrm{~s}^{-1}$ and $5.46 \times 10^{-7} \mathrm{~s}^{-1}$ respectively. Although studies by Neeb et al. (1997) report a time lag between $d[\mathrm{HC}(\mathrm{O}) \mathrm{OH}] / d t$ and $-d\left[\mathrm{O}_{3}\right] / d t$ indicating secondary heterogeneous $\mathrm{HC}(\mathrm{O}) \mathrm{OH}$ production, this is not apparent here and so is not concordant with this study.

\subsection{Loss of $\mathrm{CH}_{2} \mathrm{OO}$}

The dominant loss process for the reaction of the simplest Criegee bi-radical, $\mathrm{CH}_{2} \mathrm{OO}$ (e.g. Taatjes et al., 2008), in the atmosphere on the one hand is not straightforward because of the lack of definitive rate coefficient data. However, it emerges from global model fields that with a rate coefficient of around $1 \times 10^{-17} \mathrm{~cm}^{3}$ molecule ${ }^{-1} \mathrm{~s}^{-1}$ reaction with $\mathrm{H}_{2} \mathrm{O}$ should dominate its loss globally. Reaction with $\mathrm{NO}_{2}$, $\mathrm{NO}$ and $\mathrm{SO}_{2}$ all compete with water at around the $5 \mathrm{ppbv}$ level (urban environment) if one assumes a rate coefficient of $1 \times 10^{-12} \mathrm{~cm}^{3}$ molecule ${ }^{-1} \mathrm{~s}^{-1}$ for these species with $\mathrm{CH}_{2} \mathrm{OO}$ in each case. However, if our estimate is correct, a value of $1 \times 10^{-17} \mathrm{~cm}^{3}$ molecule ${ }^{-1} \mathrm{~s}^{-1}$ is probably too small, leading to the conclusion that reaction with water dominates nondecompositional loss in the background atmosphere. Taking the initial analysis at face value and assuming that the production curve (be it considered scenario 1, scenario 2, or some combination) is correct, this study places an upper limit of about $65 \%$ for the yield of $\mathrm{HC}(\mathrm{O}) \mathrm{OH}$ from the decomposition of $\mathrm{CH}_{2} \mathrm{OO}$ formed in the atmosphere (from ethene ozonolysis). The $65 \%$ corresponds to a typical water vapour levels encountered where ethene oxidation occurs in the model. If it is assumed that $\mathrm{HC}(\mathrm{O}) \mathrm{OH}$ can only be formed from stabilised $\mathrm{CH}_{2} \mathrm{OO}$ then the maximum is $54 \%$ (Alam et al., 2011), which is reached assuming a water concentration of around $6 \times 10^{17}$ molecule $\mathrm{cm}^{-3}$.

\section{Model results}

Data from this study for the ratio of decomposition of $\mathrm{CH}_{2} \mathrm{OO}$ with reaction with water to produce $\mathrm{HC}(\mathrm{O}) \mathrm{OH}$ has been used in the base case global model integration. In the model there are two photochemical sources of $\mathrm{CH}_{2} \mathrm{OO}$, ozonolysis of ethene and ozonolysis of isoprene. The base case integration produces 1.0 or $0.8 \mathrm{Tg} \mathrm{yr}^{-1} \mathrm{HC}(\mathrm{O}) \mathrm{OH}$ assuming either 0.65 or 0.52 as the yield from the ozonolysis of ethene. For the ozonolysis of isoprene, it is assumed that the yield of $\mathrm{CH}_{2} \mathrm{OO}$ is $\sim 0.6$, where the biradical is a product partner on formation of either methylvinyl ketone or methacrolein. If we assume that $\mathrm{HC}(\mathrm{O}) \mathrm{OH}$ can only be formed from stabilised $\mathrm{CH}_{2} \mathrm{OO}$ and that this is limited to 0.52 , the formation of $\mathrm{HC}(\mathrm{O}) \mathrm{OH}$ from $\mathrm{CH}_{2} \mathrm{OO}$ formed from the ozonolysis of isoprene we arrive at a yield of $9.5 \mathrm{Tg} \mathrm{yr}^{-1}$. Effectively this a total yield of about 0.3 and is consistent with Neeb et al. (1996). However, if we assume that the yield of formic acid increases with water vapour according to relationship established in Fig. 6, the temperatures and relative humidities encountered where isoprene is present in the model (i.e. tropics) produces yields of between 0.65 to 0.8 leading to a yield of 11.5 to $14.5 \mathrm{Tg} \mathrm{yr}^{-1}$. In addition reaction of $\mathrm{OH}$ with acetylene (ethyne) yields $3.7 \mathrm{Tg} \mathrm{yr}^{-1}$ and from direct emissions, $5.5 \mathrm{Tg} \mathrm{yr}^{-1}$ biomass burning and $1.8 \mathrm{Tg} \mathrm{yr}^{-1}$ anthropogenic sources (combustion) giving a total source of 21.3 to $26.5 \mathrm{Tg} \mathrm{yr}^{-1}$. Hence the base case produces 14 to $19.2 \mathrm{Tg} \mathrm{yr}^{-1}$ from photochemical and $7.3 \mathrm{Tg} \mathrm{yr}^{-1}$ from direct emissions compared with a recent estimate of $48.6 \mathrm{Tg} \mathrm{yr}^{-1}$ from photochemical and $8.1 \mathrm{Tg} / \mathrm{year}$ from direct emissions (Paulot et al., 2011). It is clear that the combined production of $\mathrm{HC}(\mathrm{O}) \mathrm{OH}$ from the ozonolysis of ethene and isoprene is very important in the model studies here and all of this arises from the reaction of $\mathrm{CH}_{2} \mathrm{OO}$ (formed from ozonolysis) with $\mathrm{H}_{2} \mathrm{O}$. Such an assertion is in agreement with other studies such as von Kuhlmann et al. (2003). Loss processes include reaction with $\mathrm{OH}(9 \%)$, wet deposition $(50 \%)$ and dry deposition $(41 \%)$, balancing the production processes. Figure 8 shows the surface level yearly average $\mathrm{HC}(\mathrm{O}) \mathrm{OH}$ from the base case integration. 
The CRI-STOCHEM model has one of the most detailed chemistry schemes for a global model, but there will be other sources of $\mathrm{CH}_{2} \mathrm{OO}$ that are not included in this model (e.g. the multitude of short-lived alkenes that are not included) and therefore the reaction of $\mathrm{CH}_{2} \mathrm{OO}$ with $\mathrm{H}_{2} \mathrm{O}$ would appear to dominate the in situ formation of $\mathrm{HC}(\mathrm{O}) \mathrm{OH}$ (as suggested by Paulot et al. (2011)). Models underestimate $\mathrm{HC}(\mathrm{O}) \mathrm{OH}$ measurements, especially over the oceans, where in-situ production following the reaction of $\mathrm{CH}_{2} \mathrm{OO}$ with water will be at its peak.

\subsection{Possible sources of $\mathrm{CH}_{2} \mathrm{OO}$ missing from the global model}

Stable products from isoprene oxidation, methyl vinyl ketone and methacrolein are included but in the simplified chemical scheme, ozonolysis does not yield $\mathrm{HC}(\mathrm{O}) \mathrm{OH}$. Using the yields of $\mathrm{CH}_{2} \mathrm{OO}$ from the work of Aschmann et al. (1996) and Grosjean et al. (1993), the yield of $\mathrm{CH}_{2} \mathrm{OO}$ is between $0.85-0.95$ and even assuming that the fraction that produces $\mathrm{HC}(\mathrm{O}) \mathrm{OH}$ is 0.52 yields around $4.3 \mathrm{Tg} \mathrm{yr}^{-1}$, and assuming a fraction of up to 0.8 yields around $6.7 \mathrm{Tg} \mathrm{yr}^{-1}$.

Monoterpenes are included in the model but assumed to react as either $\alpha$-pinene or $\beta$-pinene and in the simplified mechanism used do not form $\mathrm{CH}_{2} \mathrm{OO}$. Lee et al. (2006) have measured the yield of $\mathrm{HC}(\mathrm{O}) \mathrm{OH}$ from ozonolysis of a series of monoterpenes and found that for $\alpha$-pinene $(\mathrm{RH}=4.1 \%)$ the yield was $7.5 \%$ and for $\beta$-pinene $(\mathrm{RH}=6.3 \%)$ the yield was $4 \%$. We recognise that the structure of the monoterpene will of course dictate whether $\mathrm{CH}_{2} \mathrm{OO}$ is formed from ozonolysis and that only $\beta$-pinene has a structure that can produce $\mathrm{CH}_{2} \mathrm{OO}$. If we assume that $\beta$-pinene represents all the monoterpene emission $\left(\sim 127 \mathrm{Tg} \mathrm{yr}^{-1}\right)$ and that the yield of nopinone (the co-product to $\mathrm{CH}_{2} \mathrm{OO}$ formation) from $\beta$-pinene ozonolysis is around $20 \%$ (Lee et al., 2006) we can invoke the 0.52 yield to produce an estimate of about $1 \mathrm{Tg} \mathrm{yr}^{-1}$, if the yield is 0.8 then this rises to about $1.5 \mathrm{Tg} \mathrm{yr}^{-1}$. Larsen et al. (2001) report $\mathrm{HC}(\mathrm{O}) \mathrm{OH}$ yields from ozonolysis of $\beta$-pinene (38\%), using these data produces $3.5 \mathrm{Tg} \mathrm{yr}^{-1}$. Adding the monoterpene, methyl vinyl ketone and methacrolein yields (up to $\sim 10 \mathrm{Tg} \mathrm{yr}^{-1}$ ) with the base case estimate produces a photochemical yield from $\sim 25-30 \mathrm{Tg} \mathrm{yr}^{-1}$, closer to the biogenic estimate of Paulot et al. (2011).

Furthermore, all 1-alkenes (Johnson and Marston, 2008) can undergo ozonolysis to yield $\mathrm{CH}_{2} \mathrm{OO}$ and subsequently $\mathrm{HC}(\mathrm{O}) \mathrm{OH}$. Hence there are myriad small sources of $\mathrm{HC}(\mathrm{O}) \mathrm{OH}$ that will contribute to global $\mathrm{HC}(\mathrm{O}) \mathrm{OH}$.

\section{Conclusions}

This study has confirmed that the yield of $\mathrm{HC}(\mathrm{O}) \mathrm{OH}$ from the ozonolysis of ethene has a strong water dependence, rising rapidly with additional water. Assuming a simple two channel model for the fate of the $\mathrm{CH}_{2} \mathrm{OO}$ radical it has been possible to estimate the ratio of the rate coefficient for the reaction with water compared $\left(k_{3}\right)$ with decomposition $\left(k_{4}\right)$. Such an analysis suggests that $k_{3}$ probably ranges between $1 \times 10^{-12}-1 \times 10^{-15} \mathrm{~cm}^{3}$ molecule $\mathrm{s}^{-1}$ and as such will indeed be the dominant loss process, other than decomposition, for this radical in the atmosphere. Global model integrations confirm that this reaction between $\mathrm{CH}_{2} \mathrm{OO}$ with water is responsible for over half the production of $\mathrm{HC}(\mathrm{O}) \mathrm{OH}$. However, $\mathrm{HC}(\mathrm{O}) \mathrm{OH}$ is still underestimated by the model. Unless there are missing biological sources, one is tempted to conclude that the myriad missing short-lived alkenes that could all contribute to $\mathrm{CH}_{2} \mathrm{OO}$ production could provide the missing source, particularly in the marine boundary layer where Reaction (R3) will be at its highest rate. Further analysis shows that monoterpene oxidation and the ozonolysis of methyl vinyl ketone and methacrolein could contribute up to $10 \mathrm{Tg} \mathrm{yr}^{-1}$ to the $\mathrm{HC}(\mathrm{O}) \mathrm{OH}$ budget.

Acknowledgements. CJP and DES gratefully acknowledge the financial support of NERC research grant reference number NE/I014381/1. KEL thanks NERC for a studentship.

Edited by: V. Faye McNeill

\section{References}

Alam, M. S., Camredon, M., Rickard, A. R., Carr, T., Wyche, K. P., Hornsby, K. E., Monks, P. S., and Bloss, W. J.: Total radical yields from tropospheric ethene ozonolysis, Phys. Chem. Chem. Phys., 13, 11002-11015, 2011.

Andreae, M. O. and Merlet, P.: Emission of trace gases and aerosols from biomass burning, Global Biogeochem. Cy., 15, 955-966, 2001.

Anglada, J. M., Aplincourt, P., Bofill, J. M., and Cremer, D.: Atmospheric formation of $\mathrm{OH}$ radicals and $\mathrm{H}_{2} \mathrm{O}_{2}$ from alkene ozonolysis under humid conditions, Chem. Phys. Chem., 3, 215-221, 2002.

Archibald, A. T., Cooke, M. C., Utembe, S. R., Shallcross, D. E., Derwent, R. G., and Jenkin, M. E.: Impacts of mechanistic changes on $\mathrm{HO}_{\mathrm{x}}$ formation and recycling in the oxidation of isoprene, Atmos. Chem. Phys., 10, 8097-8118, doi:10.5194/acp10-8097-2010, 2010.

Arlander, D. W., Cronn, D. R., Farmer, J. C., Menzia, F. A., and Westberg, H. H.: Gaseous Oxygenated Hydrocarbons in the Remote Marine Troposphere, J. Geophys. Res.-Atmos., 95, 1639116403, 1990.

Aschmann, S. M., Arey, J., and Atkinson, R.: OH radical formation from the gas-phase reactions of $\mathrm{O}_{3}$ with methacrolein and methyl vinyl ketone, Atmos. Environ., 30, 2939-2943, doi:10.1016/1352-2310(96)00013-1, 1996.

Atkinson, R., Baulch, D. L., Cox, R. A., Hampson, R. F., Kerr, J. A., Rossi, M. J., and Troe, J.: Evaluated kinetic and photochemical data for atmospheric chemistry: Supplement VIII, halogen species - IUPAC Subcommittee on Gas Kinetic Data Evaluation for Atmospheric Chemistry, J. Phys. Chem. Ref. Data, 29, 167266, 2000. 
Atkinson, R., Baulch, D. L., Cox, R. A., Crowley, J. N., Hampson, R. F., Hynes, R. G., Jenkin, M. E., Rossi, M. J., and Troe, J.: Evaluated kinetic and photochemical data for atmospheric chemistry: Volume II - gas phase reactions of organic species, Atmos. Chem. Phys., 6, 3625-4055, doi:10.5194/acp-6-3625-2006, 2006.

Broadgate, W. J., Liss, P. S., and Penkett, S. A.: Seasonal emissions of isoprene and other reactive hydrocarbon gases from the ocean, Geophys. Res. Lett., 24, 2675-2678, 1997.

Bauerle, S., and Moortgat, G. K.: Absorption cross-sections of $\mathrm{HOCH}_{2} \mathrm{OOH}$ vapor between 205 and $360 \mathrm{~nm}$ at $298 \mathrm{~K}$, Chem. Phys. Lett., 309, 43-48, 1999.

Calvert, J. G., Su, F., Bottenheim, J. W., and Strausz, O. P.: Mechanism of Homogeneous Oxidation of Sulfur-Dioxide in Troposphere, Atmos. Environ., 12, 197-226, 1978.

Calvert, J. G., Atkinson, R., Kerr, J. A., Madronich, S., Moortgat, G. K., Wallington, T. J., and Yarwood, G., The Mechanism of Atmospheric Oxidation of the Alkenes, Oxford University Press, New York, USA, 2000.

Chebbi, A. and Carlier, P.: Carboxylic acids in the troposphere, occurrence, sources, and sinks: A review, Atmos. Environ., 30, 4233-4249, 1996.

Collins, W. J., Stevenson, D. S., Johnson, C. E., and Derwent, R. G.: Tropospheric ozone in a global-scale three-dimensional Lagrangian model and its response to NOx emission controls, J. Atmos. Chem., 26, 223-274, 1997.

Crehuet, R., Anglada, J. M., and Bofill, J. M.: Tropospheric formation of hydroxymethyl hydroperoxide, formic acid, $\mathrm{H} 2 \mathrm{O} 2$, and $\mathrm{OH}$ from carbonyl oxide in the presence of water vapor: A theoretical study of the reaction mechanism, Chem.-Eur. J., 7, $2227-$ 2235,2001

Cremer, D., Kraka, E., and Szalay, P. G.: Decomposition modes of dioxirane, methyldioxirane and dimethyldioxirane - a CCSD(T), MR-AQCC and DFT investigation, Chem. Phys. Lett., 292, 97 109, 1998

Derwent, D., Jenkin, M., Passant, N., and Pilling, M.: Up in the air, Chem. Ind., 18-19, 2008

Granier, C., Guenther, A., Lamarque, J. F., Mieville, A., Muller, J. F., Olivier, J., Orlando, J., Peters, J., Petron, G., Tyndall, G., and Wallens, S.: POET, a database of surface emissions of ozone precursors available online at: http://www.aero.jussieu.fr/projet/ ACCENT/POET.php, 2005.

Grosjean, D., Williams, E. L., and Grosjean, E.: Atmospheric chemistry of isoprene and of its carbonyl products, Environ. Sci. Technol., 27, 830-840, doi:10.1021/es00042a004, 1993.

Hatakeyama, S., Bandow, H., Okuda, M., and Akimoto, H.: Reactions of $\mathrm{CH}_{2} \mathrm{OO}$ and $\mathrm{CH}_{2}$ (1a1) with $\mathrm{H}_{2} \mathrm{O}$ in the Gas-Phase, J. Phys. Chem., 85, 2249-2254, 1981.

Henze, D. K., Seinfeld, J. H., Ng, N. L., Kroll, J. H., Fu, T. M., Jacob, D. J., and Heald, C. L.: Global modeling of secondary organic aerosol formation from aromatic hydrocarbons: highvs. low-yield pathways, Atmos. Chem. Phys., 8, 2405-2420, doi:10.5194/acp-8-2405-2008, 2008.

Jacob, D. J.: Chemistry of $\mathrm{OH}$ in Remote Clouds and Its Role in the Production of Formic-Acid and Peroxymonosulfate, J. Geophys. Res.-Atmos., 91, 9807-9826, 1986.

Jenkin, M. E., Watson, L. A., Utembe, S. R., and Shallcross, D. E.: A Common Representative Intermediates (CRI) mechanism for VOC degradation. Part 1: Gas phase mechanism development,
Atmos. Environ., 42, 7185-7195, 2008.

Johnson, D. and Marston, G.: The gas-phase ozonolysis of unsaturated volatile organic compounds in the troposphere, Chem. Soc. Rev., 37, 699-716, 2008.

Kawamura, K., Steinberg, S., Ng, L., and Kaplan, I. R.: Wet deposition of low molecular weight mono- and di-carboxylic acids, aldehydes and inorganic species in Los Angeles, Atmos. Environ., 35, 3917-3926, 2001.

Keene, W. C. and Galloway, J. N.: Considerations Regarding Sources for Formic and Acetic-Acids in the Troposphere, J. Geophys. Res.-Atmos., 91, 14466-14474, 1986.

Keene, W. C., Galloway, J. N., and Holden, J. D.: Measurement of Weak Organic Acidity in Precipitation from Remote Areas of the World, J. Geophys. Res.-Ocean. Atmos., 88, 5122-5130, 1983.

Kroll, J. H., Sahay, S. R., Anderson, J. G., Demerjian, K. L., and Donahue, N. M.: Mechanism of HOx formation in the gas-phase ozone-alkene reaction. 2. Prompt versus thermal dissociation of carbonyl oxides to form OH, J. Phys. Chem. A, 105, 4446-4457, $2001 \mathrm{a}$.

Kroll, J. H., Sahay, S. R., Anderson, J. G., Demerjian, K. L., and Donahue, N. M.: Mechanism of HOx formation in the gas-phase ozone-alkene reaction. 2. Prompt versus thermal dissociation of carbonyl oxides to form OH, J. Phys. Chem. A, 105, 4446-4457, $2001 b$.

Larsen, B. R., Di Bella, D., Glasius, M., Winterhalter, R., Jensen, N. R., and Hjorth, J.: Gas-phase $\mathrm{OH}$ oxidation of monoterpenes: Gaseous and particulate products, J. Atmos. Chem., 38, 231-276, doi:10.1023/A:1006487530903, 2001

Leather, K. E., McGillen, M. R., and Percival, C. J.: Temperaturedependent ozonolysis kinetics of selected alkenes in the gas phase: an experimental and structure-activity relationship (SAR) study, Phys. Chem. Chem. Phys., 12, 2935-2943, 2010.

Leather, K. E., McGillen, M. R., Ghalainey, M., Shallcross, D E., and Percival, C. J.: Temperature-dependent kinetics for the ozonolysis of selected chlorinated alkenes in the gas phase, Int J. Chem. Kinet., 43, 120-129, 2011.

Lee, A., Goldstein, A. H., Keywood, M. D., Gao, S., Varutbangkul, V., Bahreini, R., Ng, L., Flagan, R. C., and Seinfeld, J. H.: Gasphase products and secondary aerosol yields from the ozonolysis of ten different terpenes, J. Geophys. Res, 111, D07302, doi:10.1029/2005JD006437, 2006

Marklund, S.: Hydroxymethylhydroperoxide as Inhibitor and Peroxide Substrate of Horseradish Peroxidase, Eur. J. Biochem., 25, 3518-3531, 1971.

McGillen, M. R., Ghalainey, M., and Percival, C. J.: Determination of gas-phase ozonolysis rate coefficients of $\mathrm{C}_{8-14}$ terminal alkenes at elevated temperatures using the relative rate method, Phys. Chem. Chem. Phys., 13, 10965-10969, 2011.

Minkoff, G. J.: The Infra-Red Absorption Spectra of Organic Peroxides, Proceedings of the Royal Society of London Series aMathematical and Physical Sciences, 224, 176-191, 1954.

Neeb, P., Horie, O., and Moortgat, G. K.: Gas-phase ozonolysis of ethene in the presence of hydroxylic compounds, Int. J. Chem. Kinet., 28, 721-730, 1996.

Neeb, P., Sauer, F., Horie, O., and Moortgat, G. K.: Formation of hydroxymethyl hydroperoxide and formic acid in alkene ozonolysis in the presence of water vapour, Atmos. Environ., 31, 1417 1423, 1997.

O’Neal, H. E. and Blumstein, C.: A New Mechanism for Gas Phase 
Ozone-Olefin Reactions, Int. J. Chem. Kinet., 5, 397-413, 1973. Orzechowska, G. E. and Paulson, S. E.: Photochemical sources of organic acids. 1. Reaction of ozone with isoprene, propene, and 2-butenes under dry and humid conditions using SPME, J. Phys. Chem. A, 109, 5358-5365, 2005.

Paulot, F., Wunch, D., Crounse, J. D., Toon, G. C., Millet, D. B., DeCarlo, P. F., Vigouroux, C., Deutscher, N. M., Abad, G. G., Notholt, J., Warneke, T., Hannigan, J. W., Warneke, C., de Gouw, J. A., Dunlea, E. J., De Maziere, M., Griffith, D. W. T., Bernath, P., Jimenez, J. L., and Wennberg, P. O.: Importance of secondary sources in the atmospheric budgets of formic and acetic acids, Atmos. Chem. Phys., 11, 1989-2013, doi:10.5194/acp-11-19892011, 2011.

Penner, J. E., Lister, D., Griggs, D., Docken, D., and MacFarland, M. (Eds.): IPCC Special Report on Aviation and the Global Atmosphere. Cambridge University Press, New York, USA, 373 pp., 1999.

Rinsland, C. P., Mahieu, E., Zander, R., Goldman, A., Wood, S., and Chiou, L.: Free tropospheric measurements of formic acid $(\mathrm{HC}(\mathrm{O}) \mathrm{OH})$ from infrared ground-based solar absorption spectra: Retrieval approach, evidence for a seasonal cycle, and comparison with model calculations, J. Geophys. Res.-Atmos., 109, D18308, doi:10.1029/2004JD004917, 2004.

Ryzhkov, A. B. and Ariya, P. A.: A theoretical study of the reactions of parent and substituted Criegee intermediates with water and the water dimer, Phys. Chem. Chem. Phys., 6, 5042-5050, 2004.

Slusher, D. L., Huey, L. G., Tanner, D. J., Flocke, F. M., and Roberts, J. M.: A thermal dissociation-chemical ionization mass spectrometry (TD-CIMS) technique for the simultaneous measurement of peroxyacyl nitrates and dinitrogen pentoxide, J. Geophys. Res.-Atmos., 109, D19315, doi:10.1029/2004JD004670, 2004.

Taatjes, C. A., Meloni, G., Selby, T. M., Trevitt, A. J., Osborn, D. L., Percival, C. J., and Shallcross, D. E.: Direct observation of the gas-phase Criegee intermediate (CH2OO), J. Am. Chem. Soc., 130, 11883-11885, 2008.

Talbot, R. W., Beecher, K. M., Harriss, R. C., and Cofer, W. R.: Atmospheric Geochemistry of Formic and Acetic-Acids at a MidLatitude Temperate Site, J. Geophys. Res.-Atmos., 93, 16381652, 1988.
Tillmann, R., Hallquist, M., Jonsson, A. M., Kiendler-Scharr, A., Saathoff, H., Iinuma, Y., and Mentel, T. F.: Influence of relative humidity and temperature on the production of pinonaldehyde and $\mathrm{OH}$ radicals from the ozonolysis of alpha-pinene, Atmos. Chem. Phys., 10, 7057-7072, doi:10.5194/acp-10-7057-2010, 2010.

Utembe, S. R., Watson, L. A., Shallcross, D. E., and Jenkin, M. E.: A Common Representative Intermediates (CRI) mechanism for VOC degradation. Part 3: Development of a secondary organic aerosol module, Atmos. Environ., 43, 1982-1990, 2009.

Utembe, S. R., Cooke, M. C., Archibald, A. T., Jenkin, M. E., Derwent, R. G., and Shallcross, D. E.: Using a reduced Common Representative Intermediates (CRIv2-R5) mechanism to simulate tropospheric ozone in a 3-D Lagrangian chemistry transport model, Atmos. Environ., 44, 1609-1622, 2010.

Utembe, S. R., Cooke, M. C., Archibald, A. T., Shallcross, D. E., Derwent, R. G., and Jenkin, M. E.: Simulating Secondary Organic Aerosol in a 3-D Lagrangian Chemistry Transport Model using the reduced Common Representative Intermediates Mechanism (CRIv2-R5), Atmos. Environ., 45, 1604-1614, 2011.

von Kuhlmann, R., Lawrence, M. G., Crutzen, P. J., and Rasch, P. J.: A model for studies of tropospheric ozone and nonmethane hydrocarbons: Model evaluation of ozone-related species, J. Geophys. Res.-Atmos., 108, 4294, doi:10.1029/2002JD002893, 2003.

Watson, L. A., Shallcross, D. E., Utembe, S. R., and Jenkin, M. E.: A Common Representative Intermediates (CRI) mechanism for VOC degradation. Part 2: Gas phase mechanism reduction, Atmos. Environ., 42, 7196-7204, 2008.

Wolff, S., Boddenberg, A., Thamm, J., Turner, W. V., and Gab, S.: Gas-phase ozonolysis of ethene in the presence of carbonyloxide scavengers, Atmos. Environ., 31, 2965-2969, 1997.

Yu, S. C.: Role of organic acids (formic, acetic, pyruvic and oxalic) in the formation of cloud condensation nuclei $(\mathrm{CCN})$ : a review, Atmos. Res., 53, 185-217, 2000. 